\title{
Research on Campus Landscape Planning Strategy Based on the Ecological Health Effect
}

\author{
Yu SHI ${ }^{\mathrm{a}}$, Yi FU ${ }^{\mathrm{a}, 1}$, Tiemao SHI ${ }^{\mathrm{b}}$, Juan $_{\mathrm{SU}}{ }^{\mathrm{b}}$ and Yaqi CHU ${ }^{\mathrm{c}}$ \\ ${ }^{a}$ School of Design and Art, Shenyang Jianzhu University, Shenyang110168, China \\ b School of Architecture College, Shenyang Jianzhu University, Shenyang110168, \\ China \\ ${ }^{\mathrm{c}}$ School of Architectural Engineering, Shenyang University, Shenyang110044, China
}

\begin{abstract}
The water landscape in college and university is the research object in this article. Through on-site investigation, monitoring and computer simulation in campus, combined with qualitative and quantitative research methods, the advantages and disadvantages of the spatial layout of the water landscape in campus are compared. In addition, the surrounding building layout and greening layout are aslo separately studied in this article. The research results show the influence mechanism of the water landscape and its spatial layout on the ecological health effect, providing a reference experience and basis for the campus ecological landscape planning.
\end{abstract}

Keywords. Landscape planning.Campus.Ecological.Health.

\section{Introduction}

As an important component of the urban landscape, the campus landscape of colleges and universities has attracted attention of domestic and foreign experts in recent years, and they have explored and studied it from different angles and aspects. As one of the five elements of landscape, water has always been the research object of theorists. Universities are reagrded as miniature cities to a certain degree, and university landscapes and urban landscapes have many similarities to some extent. The study of urban waterscapes has certain reference and significance for the waterscapes of universities [1].

There are many practical researches on the water quality of the water landscape. For example, Jin Yuanhuan proposed NARS water purification technology based on the current problems in the waterfront area, through the traditional physical methods, chemical methods, oxygenation methods, microbial methods and aquatic plant restoration. Due to those methods as the foundation of water control, the NARS water purification system with comprehensive treatment based on the method of naturalization has been developed [2]. Natural Waters based on the actual monitoring data of 26 lakes, reservoirs and rivers distributed in China, combined with theoretical

\footnotetext{
${ }^{1}$ Yi Fu, School of Design and art, Shenyang Jianzhu University, Shenyang110168, China; E-mail:
} 6905036@qq.com. 
analysis, explores the characteristics and laws of various waters climate effects under different natural conditions, and gives the approximate numerical range of its positive and negative effects on temperature, humidity, wind speed and precipitation. [3] There are also research related to the microclimate effect of small waters of urban, such as the Small Artificial Landscape Water Body Biochar Enhanced Water Quality Control Technology and Human Comfort in Waterfront Environment, this article conducts onsite field measurement and inspection of waterfront environments of different sizes, and obtains the relationships among water bodies, vegetation, wind conditions and cooling and humidification, combined with the theory of water evaporation, cooling and humidification and heat index, the calculation formula is used to establish a human comfort impact evaluation model suitable for the waterfront environment. Finally, it is proposed that the human body feels the most comfortable in a certain area in the waterfront area of Shanghai. In the waterfront area without plants, the waterfront distance is 10 to $12 \mathrm{~m}$. In the waterfront area with green waterfront area, the human body feels the most comfortable in the area about 14 meters away from the water body [4]. Another example, Liu Hong article Study on the Ecological Effects of Artificial Lakes selects an artificial lake from Henan Institute of Science and Technology with measurement and inspection for the temperature and humidity of the surrounding environment. The relationships among the water area, the distance to the water and the ecological health effect of the artificial lake are studied. In addition, the water-green compound method is more conducive to the ecological health effect of the artificial lake. These actual measurements and research methods on the ecological health effects of small urban waters have greatly inspired the basic research on the ecological health effects of water bodies in this article [5]

The simulation and analysis of the ecological effects of water bodies started as early as the 1990s. As an expert in this field, Fu Baopu has a lot of related researches. For article Effects of Inland Water Body on Ambient Air Specific Humidity published in 1993, by establishing a non-static approximate small-scale numerical model of physical processes on the ground and in the water body, the spatial distribution of the influence of the water body on the specific humidity of the surrounding air is simulated [6]. The calculation shows that the water body has a humidification effect in winter and summer. The extent of isincreasing is that the sunny days are greater than cloudy days, the night is greater than the day, and the winter is greater than summer season.

Computer simulation technology is widely used in the design and research of indoor environment, and the its application on outdoor environment is just on the primary stage in China. The Building Environment Joint Laboratory has done some work in this regard, using the improved Cluster Thermal Time Constant (CTTC) model combined with the Computational Fluid Dynamics (CFD) simulation methods to comprehensively consider the impact of solar radiation, greening measures and building layout on the thermal environment. It is useful to predict and evaluate the thermal environment in different areas of residential communities around the waterfront environment and give evaluation indicators. The book writed by Li Shuyan et al. Analysis of Microclimate Effects of Water Body in A City, uses observational data analysis and numerical simulation methods to study the water in the city. It is concluded that the area and layout of water bodies are important factors affecting the microclimate effect [7]. In recent years, some dissertations have also begun to use fluid mechanics software for verification, Wu Jing' article Study on the Adaptability of Waterfront Landscape in Hot Summer and Cold Winter Regions to Optimization and Improvement Strategies for Human Settlements-Taking the Wuhan Lake Region as the 
Research Object [8], the computer software simulations are used to explore the adaptive optimization design strategies of waterfront landscapes in hot summer and cold winter areas to the human settlement environment.

\section{Materials and Methods}

\subsection{Basic Ecological Functions of Water Landscape in Microenvironment}

\subsubsection{Regulation of Microclimate}

The water bodies in the general microenvironment play an important role in regulating the microclimate of the environment and improving the climate in local areas of the city. In particular, the reasonable configuration of water bodies combined with plants and terrain can form a good condition of microclimate. This is mainly manifested in several aspects such as adjusting the environmental temperature and humidity, increasing negative oxygen ions, vacuuming and reducing noise. Since the evaporation of water needs to absorb heat, the evaporation of water in the hot summer can achieve the effect of cooling. In the dry seasons of autumn and winter, the evaporation of water can also increase the air humidity in the surrounding area. The water irradiated by the sun evaporates into water vapor when it rises into the air to form a negative air pressure, so the surrounding cooler air enters and supplements the vacancy, which strengthens the natural ventilation of a certain area. In addition, the water environment can moisten the ground surface, and effectively avoid the weathering of soil and rocks, and also play a certain balance for the groundwater circulation in the area [9]. The degree of adjustment of the water landscape to the environment and climate is related to the surface area of the water body and the layout of the water body. As a kind of microenvironment, the campus can take corresponding measures to control the environmental elments such as humidity, temperature and wind to create a pleasant and comfortable environment. For example, it is possible to moderately expand the area of water bodies to adjust the microclimate. Further, it is necessary to choose a suitable water body layout to meet the needs of a certain ecological benefit of the campus. It is also important to properly configure greening to block noise and adjust the sun exposure.

\subsubsection{Improving Air Quality and Blocking Noise}

The water body can absorb dust and smoke in the air, playing a role in improving air quality, which is helpful to improve the microenvironment. In addition, when the water body moves in the air, it collides with air molecules to generate a large amount of negative oxygen ions. There must be a certain amount of water for the production of negative air ions, and the concentration of negative air ions will increase with the increase of environmental humidity. The air negative ions have the functions of sterilizing, reducing dust and improving the body's immunity. They are called as air vitamins, which are beneficial to the body's physical and mental health [10].

The water body can reduce noise by blocking, especially in the city, such as the end of the car, the noise of the factory, etc., can be blocked by the waterscape. In the campus environment, dynamic waterscapes and human activities can be combined, and the surrounding noise can be covered by the beautiful water sounds, which can control the noise to a certain extent and create a peaceful and pleasant environment. 


\subsubsection{Maintain Biodiversity}

The ecological waterscape in the microenvironment is not only a beautiful scenery in the environment, but also provides a good habitat for fish, waterfowl, birds, amphibians, aquatic plants and microorganisms. Especially if the wetland or constructed wetland has existed in the area itself, its natural structure can form a natural community structure and ecosystem, which can provide a good habitat for a large number of animals and plants, and is conducive to the protection of biodiversity [11 ].

Biodiversity is a necessary condition for the continuation of human survival. However, species that live with water have gradually decreased or even disappeared with the development of urbanization. Maintaining biodiversity does not depend on large urban lakes and wetlands. Small water systems are also suitable for the protection of animals and plants. Therefore, a pond can be built in the microenvironment, and local aquatic plants can be planted in the pond, and wildflowers, shrubs and trees can be planted on the shore to attract insects, birds and small animals to form a complete small water system biological community [12]. In college, the small water systems and green spaces are also needed to connected as much as possible to form an ecosystem, so that organisms can migrate among sections through corridors, which is more conducive to the formation and protection of ecological system of the entire campus.

\subsubsection{Disaster Prevention and Water Storage}

Water bodies in the microenvironment, especially water body of large areas can accumulate rainwater during the rainy season to reduce the pressure on municipal sewage discharge and reduce flooding. On the one hand, the accumulated rainwater can be used to irrigate flowers, trees and grassland and so on and it can also be used to wash the ground, flush toilets and so on. On the other hand, the accumulated rainwater can be used as landscape water after treatment, even in dry seasons and disasters occuring, it can be used as domestic water for drinking and washing, and it can also be used in disaster relief such as fire fighting

Waterscape construction should achieve the purpose of preventing floods and conserving water sources by building safe waterfront lines and reasonably transforming the waterfront environment and other methods. Ecological revetments made of natural materials should be used to form a permeable surface. During the high water period, the water can penetrate downward and store to alleviate the flood disaster. During the low water period, the groundwater replenishes water to adjust the water level. It is important to plant a large amount of vegetation on the waterfront,which is is hepful for soil and sand fixation to enhance the stability of the waterfron.

\subsection{Simulation and Calculation Method for Water Landscape}

This paper studies the spatial layout of campus water landscape based on ecological health effects. Most parameters adopted are from meteorological data of Shenyang, Changchun and Beijing. The meteorological parameters of these cities basically refer to the relevant specifications of the Design Code for Heating Ventilation and Air Conditioning of Industrial Buildings, as well as the average meteorological parameter data of these cities after many years of observation and measurement. Since the ecological effect of water bodies in winter is not as good as in summer, and Shenyang has a long and severe winter, and the water surface is frozen, its water vapor evaporation is negligible. This paper only considers the improvement effect of water 
bodies on the thermal environment in summer. The main meteorological parameters including the calculation temperature of ummer ventilation outdoor, calculation humidity of summer ventilation outdoor, average wind speed, dominant wind, water temperature, building exterior surface temperature and so on. The water temperature is based on the on-site measurement by the author itself. The pioneers' valuable experience in studying the water body of the city can be referred this time. The outer surface temperature of the building is the comprehensive temperature under solar radiation, the formula is: $\mathrm{Tz}=\mathrm{Tw}+\rho \mathrm{I} / \alpha \mathrm{w}$. The so-called comprehensive temperature is equivalent to the sum of the outdoor air temperature from the original Tw value and an equivalent temperature of solar radiation $\rho \mathrm{I} / \alpha \mathrm{w} . \rho$ is the absorption coefficient of the solar radiation on the surface of the enclosure structure. $I$ is the intensity of solar radiation, and $\alpha \mathrm{w}$ is the convection heat transfer coefficient on the outer surface. This paper is mainly based on consulting the relevant data of the outer surface temperature of the building under solar radiation, taking the empirical value of solar radiation value at $1 \mathrm{pm}$ in each area. The setting of these climate parameters is basically reflected in the establishment of the first step of model modeling (Zoom), which the Zoom is the whole natural environmental condition. that occur in the model. These meteorological conditions including water temperature and building exterior surface temperature, need to be entered when creating sources and entities. The volume of the computational Zoom is required to be larger than that of the simulation object. It is advisable to take the length and width of each surface to be 3-6 times the length and width of the campus.

The model selects the plane size of a general-scale campus, with a length of $1000 \mathrm{~m}$ and a width of $1000 \mathrm{~m}$. First, the temperature and humidity effects of water bodies is quantitatively studied. Then four square water models of $5,000 \mathrm{~m}^{2}, 10,000 \mathrm{~m}^{2}, 20,000$ $\mathrm{m}^{2}$, and $40,000 \mathrm{~m}^{2}$ in the center of the region are established. The calculation Zoom in the model is selected according to the actual situation. For the east, west, south and north sides of the model, each selects 3 times the length and width of the campus, and the height direction is also 3 times. The water area in the model is set as the source of the emission material. The temperature of the water body varies with the seasons with great fluctuations. To simplify the model, the author did not consider that the existence of the water system would change the moisture content of the surrounding soil, resulting in humidity changes of the surrounding air. At the same time, the following assumptions are made that the fluid is a low-velocity incompressible fluid, a turbulent flow with stable hourly average velocity, which satisfies the Boussinesq hypothesis. The simulation results show that the water body has a certain temperature effect and humidity effect. In order to study the quantitative relationships between the temperature and humidity effect of the area sizes of the water body, in this simulation, it is an ideal environment without buildings and the water body area is set $5,000 \mathrm{~m}^{2}$, $10,000 \mathrm{~m}^{2}, 20,000 \mathrm{~m}^{2}$, and $40,000 \mathrm{~m}^{2}$. These square water areas are located in a campus with an area of $1000 \mathrm{~m}^{*} 1000 \mathrm{~m}$. The ecological benefits of the water body studied in this paper can reach a height of $18 \mathrm{~m}$. Therefore, three heights of $1.5 \mathrm{~m}, 9 \mathrm{~m}$ and $18 \mathrm{~m}$ are selected to complete the simulation.

The micro-environments with the water areas of $5,000 \mathrm{~m}^{2}, 10,000 \mathrm{~m}^{2}, 20,000 \mathrm{~m}^{2}$, and $40,000 \mathrm{~m}^{2}$ are taken as representatives. The reason why the area is increased doubly is to analyze the numerical influence relationship of different water area sizes on the effect of cooling and humidification. It can be seen from the simulation results that the cooling and humidification effect of the water body is greater as the area of the water body increases. When the water area is $5,000 \mathrm{~m}^{2}$, the maximum temperature drop is $1.4^{\circ} \mathrm{C}$, and the maximum humidification increasing is $10.2 \%$. When the water area 
increases to $40,000 \mathrm{~m}^{2}$, the maximum temperature drop reaches $3.4^{\circ} \mathrm{C}$, and the maximum humidification increasing reaches $26 \%$.

Table 1. The amount of water cooling and humidification in different area.

\begin{tabular}{ccc}
\hline \multirow{2}{*}{ Water area $\left(\right.$ Ten thousand $\left.\mathrm{m}^{2}\right)$} & \multicolumn{2}{c}{ Simulation value } \\
\cline { 2 - 3 } & Temperature drop $\left({ }^{\circ} \mathrm{C}\right)$ & Humidification inreasingn $(\%)$ \\
\hline 0.5 & 1.4 & 10.2 \\
1 & 1.8 & 13.7 \\
2 & 2.17 & 15.3 \\
4 & 3.4 & 26 \\
\hline
\end{tabular}

The relationships among the temperature drop, humidification incerasing and the area of the water body are showed as the table 1. It can be seen that the first regression correlation coefficients of the temperature drop and humidification incerasing between the area of the water body are respectively 0.99 and 0.98 . According to the significance test theory of data regression, it shows that there is a good second order correlation.

\section{Results}

\subsection{Simulation and Analysis of Water Landscape in Shenyang Jianzhu University}

The Shenyang Jianzhu University is the studied area as an example. The plane figures are taken with Google earth. Because the author mainly considers the simulation results at a pedestrian height of $1.5 \mathrm{~m}$, many low-rise buildings on the campus are not included into the simulation. In order to simplify the model and facilitate calculations, the building groups are changed to be more straight and tidy based on the actual campus plane. The modified building complex is shown in the simulation diagram. The water body is mainly composed of a central water system of $27,000 \mathrm{~m}^{2}$. The paddy landscape irrigated in summer is also included in the scope of this simulation as a water body, which is about $8,000 \mathrm{~m}^{2}$. The wetland in the southwest corner is about $27,000 \mathrm{~m}^{2}$.

Shenyang is a city which the temperature is not high all year round. The winter is long and severely cold, and the temperature is very low with frozen water surface, so the water vapor evaporation of the water system is negligible. Therefore, the author only discusses the ecological effect of the water system in summer. The calculated temperature of summer ventilation outdoor in Shenyang area is $28.2^{\circ} \mathrm{C}$. The calculated humidity of summer ventilation outdoor is $64 \%$. The average summer wind speed is 2.9 $\mathrm{m} / \mathrm{s}$. The dominant wind direction in summer is south, and the water temperature in summer is $18^{\circ} \mathrm{C}$. The exterior surface temperature of the building is $31.5^{\circ} \mathrm{C}$ based on the formula, relevant information, data and previous experience through actual measurement.

The calculation Zoom is determined based on actual situation. For the east, west, south and north sides of the model, each selects 3 times the length and width of the campus, and the height direction is 2-3 times the height of the building. The two tallest student dormitories are about $51 \mathrm{~m}$, and the remainings are $18 \mathrm{~m}$, and the teaching building is $15 \mathrm{~m}$. The exit of the computing Zoom is set to opening. Namely, it is assumed that the campus is the same as in this simulation. The water body is set as the 
source of the emitted materials, and the temperature of the water fluctuates greatly with the seasonal changes, so the temperature of river water is set to $18{ }^{\circ} \mathrm{C}$ in summer.

\subsubsection{Temperature Distribution on Campus.}

The temperature of the campus area away from the water area is between $28.8^{\circ} \mathrm{C}$ $29.6^{\circ} \mathrm{C}$. The temperature of the area closer to the central water system is between $25.8^{\circ} \mathrm{C}-27.4^{\circ} \mathrm{C}$. The temperature of the area closer to the paddy landscape is between $26.4^{\circ} \mathrm{C}-28^{\circ} \mathrm{C}$. The temperature in the area near the southwest corner of the wetland is between $27^{\circ} \mathrm{C}$ and $28.2^{\circ} \mathrm{C}$. It can be seen from the simulation diagram that the influence of the water body on the temperature is greatly influenced by the wind direction, which the influence range of the downwind direction is much larger than that of the upwind direction. The central water system has the largest area and the widest range of influence, which has a great effect on cooling the surrounding areas and buildings. The paddy landscape and wetland play a certain role in regulating the temperature of the teaching building in the west. Because the ground floor is overhead, the temperature in the courtyard is reduced to a certain extent. Because the temperature of the water body is low, and the water surface evaporates with heat absorption, it not only improves the comfort of the human body in terms of temperature, but also affects the human's adaptability to cold and heat psychologically.

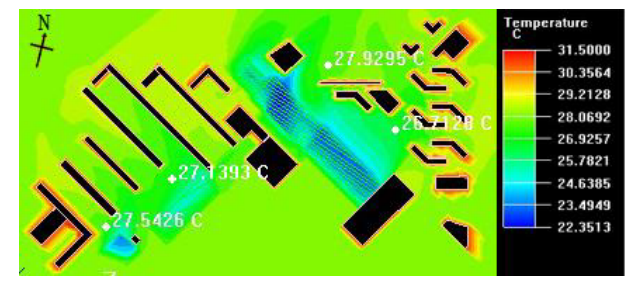

Figure 1. Temperature contour in Shenyang JianZhu University.

Water inspires people to pursue nature and makes people abtain pleasure, thereby distracting people from the heat sensation. Even when the temperature on the campus becomes a little higher, people will not feel particularly hot psychologically. The temperature distribution is shown in figure 1.

\subsubsection{Relative Humidity Distribution on Campus}

The relative humidity of the area away from the water is between $62.7 \%$ and $64 \%$. The relative humidity of the area closer to the central water system is between $71.7 \%$ and $85 \%$. the relative humidity of the area closer to the paddy landscape is between $69.9 \%$ and $74.9 \%$. The relative humidity in the area closer to the southwestern wetland is between $66.7 \%$ and $72.9 \%$. The distribution of relative humidity has the same law as the temperature. The farthest end of the influence of the central water system on relative humidity is at a distance of $200 \mathrm{~m}$ from the downwind direction, and the humidification incrasing is $7.8 \%$. It can be seen that the existence of the water system has a certain impact on the relative humidity of the campus (figure 2). 


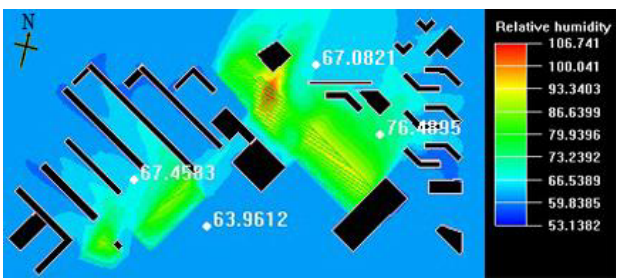

Figure 2. Relative humidity contour in Shenyang JianZhu University.

\subsection{Analysis of Water Landscape and Building Greening Layout}

The building is located in the downwind of summer dominant wind of the water landscape which is the best choice. Considering the ventilation in summer and wind protection in winter in Shenyang, it is better to place the building on the west, north and east sides of the water body.

For a rectangular water body in the campus, its long axis should be placed in the vertical direction of the summer dominant wind, which is conducive to striving for the maximum water vapor diffusion under the direction of wind. The layout of buildings along the water system has been simulated to verify that the ecological effect of the diagonal building layout is the best, and the ecological environments of determinant and diagonal layouts are basically the same. If buildings need to be arranged on both sides of the water body, the diagonal layouts are adopted on both sides of the water body for promotion of summer ventilation to ensure the ecological health effects on both sides of the water body, which is also the best choice.

The diagonal building layout along the downwind direction of the water system only has ecological health effects on the two rows of buildings. For cold areas, the taller buildings should be placed on the northernmost side in the building facade design, which can make the surrounding buildings and nearby ecological environment the best in summer and is helpful for taking wind-proof measures to reduce heat loss of the building in winter.

It is verified through actual measurement that the water body has a better cooling and humidification effect on the surrounding environment than greening. In the planning, the water body-greening compound design can produce better ecological health effects. In cold regions, the water body is placed in the upwind direction of summer dominant wind. Arbor trees are planted on both sides of the water body, which can guide the incoming wind to blow to the building through the water surface and improve the microclimate around the building. The thick bushes or tall evergreen coniferous trees should be planted in the unwind direction of winter dominant wind of buildings to form a natural wind barrier.

\section{Conclusion}

This paper mainly discusses the influence factors of different water landscape space on the ecological health effect. The Airpak software is used to carry out numerical simulation. When the pedestrian height is $1.5 \mathrm{~m}$, the temperature and relative humidity (RH) are obtained respectively. Through the climate monitoring indoor and outdoor in Shenyang JianZhu University, the temperature changes and the relative humidity changes are compared with the simulated values. Although the surrounding 
environment of the water system of the campus is different, the temperature and relative humidity also have corresponding changes. Data and values about the influence of water landscape and building greening layout on ecological health effects are abtained to provide relevant basis for campus ecological planning.

\section{Acknowledgements}

Funding for this paper was provided by the National Natural Science Foundation of China (No.52008267).

\section{References}

[1] Clarkson PJ, Coleman R. History of inclusive design in the UK. Applied Ergonomics. 2015 Apr; 46 (Part B): 235-247.

[2] Imrie R, Kumar M. Focusing on disability and access in the built environment Disability and Society. 1998 Jul; 13 (3): 357-374.

[3] Fu BQ. Water climate effects under different natural conditions in China. Acta Geographica Sinica. 1997 May; (6).

[4] Jiang C. Research on humanized landscape design in the construction of parks and green spaces. Nanjing: Nanjing Forestry University; 2010.

[5] Sui DZ. GIS, cartography, and the"Third Culture": Geographic imaginations in the computer age. Professional Geographer. 2004 Feb; 56 (1) 62-72.

[6] Bodenhamer DJ, Corrigan J, Harris TM. The spatial humanities: GIS and the future of humanities scholarship. Indianapolis: Indiana University Press; 2010. p.14-30.

[7] Li SY. Research on the microclimate effects of water in cities. Chinese Journal of Atmospheric Sciences. 2008 Jan; (5): 552-560.

[8] Wu J. Research on the adaptability optimization and improvement strategy of the waterfront landscape in the area of hot summer and cold winter to the human settlement environment-Taking Wuhan Lake Area as the Research Object. Wuhan: Huazhong University of Science and Technology; 2006.

[9] Schroeder HW. Place experience, gestalt, and the human-nature relationship Journal of Environmental Psychology. 2007 Dec; (4): 293-309.

[10] Jin YH. Ecological design and comprehensive management of urban waterscapes-Building a clear and beautiful original ecological waterscape system. Beijing: China Water\&Power Press; 2006.

[11] Carmon N. Neighborhood regeneration: The state of the art. Journal of Planning Education and Research. 1997 Dec; 17 (2): 131-144.

[12] Roberts P, Sykes H, Granger R. Urban Regeneration. London: SAGE Publications Ltd; 2016. 